\title{
GOVERNMENTAL SOURCES DALAM KEBIJAKAN LUAR NEGERI AMERIKA SRIKAT TERKAIT RENEGOSIASI KESEPAKATAN NORTH AMERICA FREE TRADE AREA (NAFTA)
}

\author{
Iqbal Ramadhan ${ }^{1}$, Trias Adelins ${ }^{1 *}$ \\ ${ }^{1}$ Program Studi Hubungan Internasional, Universitas Pertamina Jakarta \\ Email: iqbal.ramadhan@universitaspertamina.ac.id, triasadelins@ gmail.com \\ *Korespondensi penulis: iqbal.ramadhan@universitaspertamina.ac.id \\ (Submission 30-04-2020, Revisions 22-04-2021, Accepted 03-06-2021)
}

\begin{abstract}
When President Trump rose to power, US government slowly but sure begin to implement inward looking policy. President Trump who has a political support from Republican Party is willing to make a renegotiation in North America Free Trade Area (NAFTA)'s trade deal. The renegotiation was intended by US government when they saw a trade deficit between United States and Mexico. The US government believed that trade deficit was making them in disadvantage position. To issue the renegotiation policy, President as a commander in chief must organize the bill based on US constitution. The political process between executive and legislative branches play pivotal role in this issue. This article aim to analyze the influence of governmental sources in US foreign policy decision making process. The author used qualitative method and case study research. The governmental sources like state political system, type of parliament, and political relations between executive and legislative has an important role in issuing NAFTA renegotiation.
\end{abstract}

Keywords: governmental sources, foreign policy, NAFTA, Trump, US government.

\begin{abstract}
Abstrak
Pasca naiknya Presiden Trump ke tampuk kepresidenan Amerika Serikat (AS), negara tersebut mulai menjalankankan berbagai macam kebijakan yang bersifat inward looking. Presiden Trump yang disokong oleh Partai Republik berkeinginan untuk melakukan renegosiasi perdagangan dalam North America Free Trade Area (NAFTA). Kebijakan renegosiasi tersebut dimulai dari ketimpangan perdagangan yang dialami oleh AS yaitu neraca perdagangan negara tersebut terhadap Meksiko mengalami defisit. Hal inilah yang mendasari pemerintah AS untuk melakukan renegosiasi kesepakatan dagang dalam NAFTA yang dinilai memberatkan mereka. Kebijakan renegosiasi NAFTA tersebut tidak terlepas dari proses politik lembaga negara seperti eksekutif dan legislatif. Artikel ini bertujuan untuk menganalisis unsur governmental sources dapat mempengaruhi proses kebijakan renegosiasi NAFTA tersebut. Metode yang digunakan dalam artikel ini adalah penelitian kualitatif dengan teknik penulisan studi kasus. Hasil analisis dalam artikel ini dapat dijelaskan bahwa unsur governmental sources seperti sistem pemerintahan, bentuk parlemen dan proses politik intra lembaga dalam pemerintah AS berperan penting terkait kebijakan renegosiasi NAFTA tersebut.
\end{abstract}


Kata kunci: governmental sources, kebijakan luar negeri, NAFTA, Trump, pemerintah AS.

\section{PENDAHULUAN}

Semenjak terpilih pada tahun 2016 menggantikan Presiden sebelumnya yaitu Barrack Obama, Presiden Donald Trump telah mengeluarkan berbagai macam kebijakan yang tidak populis. Presiden Trump terpilih melalui kemenangan pemilu Amerika Serikat (AS) yang diusung oleh Partai Republik. Mengutip dari New York Times yang merangkum drama pemilu di AS, Presiden Trump dan Partai Republik berhasil mengungguli kandidat lainnya dari Partai Demokrat yaitu Hillary Clinton dengan keunggulan 306 berbanding 232 suara (NY Times, 2017). Pasca kemenangan pemilu tersebut, Presiden Trump dalam beberapa pidato kepresidennya menyinggung tentang kebijakan America First (Trump, 2016). Kebijakan tersebut menjadi tanda bahwa pemerintah AS akan memprioritaskan kepentingan negaranya di atas negara lain. Di masa pemerintahannya, Presiden Trump setidaknya telah menarik mundur negaranya dari COP 21 Paris Agreement karena dianggap membebani pemerintah AS dalam bidang ekonomi (Pompeo, 2019). Selain itu, Presiden Trump menyatakan bahwa AS tidak lagi tergabung dalam perjanjian Trans Pacific Partnership (TPP) karena dalam perjanjian tersebut Tiongkok merupakan salah satu anggotanya (Anjani, 2018). Hal ini menjadi kekhawatiran utama AS yang menganggap Tiongkok sebagai rival utama mereka dalam bidang ekonomi.

Kebijakan luar negeri yang kini bersifat inward looking tersebut memang tidak terlepas dari kultur Partai Republik yang mengusung Trump maju menjadi Presiden AS. Menurut John Mearsheimer dan Stephen M. Walt (2008), Partai Republik secara kultur politik memandang bahwa hegemoni dan nilai-nilai yang dimiliki oleh AS harus disebar ke seluruh dunia dengan cara apapun. Oleh karenanya, munculah citra bahwa Partai Republik merupakan partai hawkish (elang) yang agresif dan tidak segan menggunakan hard power untuk mencapai kepentingan nasionalnya (Mearsheimer \& Walt, 2008). Tentunya ini bertentangan dengan pendekatan kebijakan luar negeri Partai Demokrat yang lebih bersifat diplomatis dan mengedepankan unsur-unsur HAM, sehingga partai tersebut dijuluki dovish (merpati) karena kebijakannya yang tidak mengedepankan hard power (Mearsheimer \& Walt, 2008). Perbedaan visi dan misi serta pandangan politik partai yang mengusung Presiden AS menjadi salah satu indikator dari bagaimana Presiden tersebut menjalankan kebijakan luar negerinya.

Kebijakan lain yang menjadi salah satu langkah gebrakan politik luar negeri Presiden Trump adalah keberaniannya untuk melakukan renegosiasi kebijakan ekonomi North America Free Trade Area (NAFTA). Kebijakan yang diambil oleh Presiden Trump tersebut cukup kontroversial mengingat pemerintah AS telah bergabung di dalamnya sejak tahun 1992 (Moran \& Abbot, 1994). Rezim internasional tersebut muncul pertama kali pada tahun 1985 yaitu CUSFTA (Canada-US. Free Trade Agreement) yang merupakan manifestasi ekonomi liberal (Moran \& Abbot, 1994). Pada tahun 1992, pemerintah AS bersama dengan Meksiko dan Kanada setuju untuk meratifikasi CUSFTA menjadi NAFTA yang bertujuan untuk meningkatkan perekonomian di masing-masing negara (Moran \& Abbot, 1994). Presiden Trump mengklaim bahwa perjanjian ekonomi yang diberlakukan di 
NAFTA khususnya hubungan perdagangan antara AS-Meksiko banyak merugikan pemerintahnya (Yuliantoro et al., 2017). Kebijakan NAFTA tersebut menurut Presiden Trump telah mendefisitkan perdagangan antara AS dan Meksiko (Yuliantoro et al., 2017). Hal ini tidaklah mengherankan karena Presiden Trump sendiri telah beberapa kali menyinggung imigran Meksiko yang menurutnya sumber kekacauan di AS (Arce, 2019).

Persoalan terbesar yang dikemukakan oleh Presiden Trump adalah arus perdagangan Meksiko dalam NAFTA yang masuk ke pasar AS lebih besar ketimbang produk mereka yang ada di pasar Meksiko. Mengutip dari Congressional Research Center (CRS) bahwa impor Meksiko ke AS pada tahun 2014 meningkat dari semula 295 miliar dollar AS menjadi 347 dollar AS (CRS, 2019). Produk komoditas perdagangan Meksiko seperti batu bara, konduktor elektronik, suku cadang kendaraan dan peralatan komputer membanjiri pasar AS lebih banyak ketimbang produk AS di pasar Meksiko. Hal ini berbanding terbalik dengan nilai total perdagangan AS ke Meksiko di tahun 2014 yang semula 241 miliar dollar AS hanya meningkat sebesar 265 miliar dollar AS (CRS, 2019). Arus perdagangan yang tidak sebanding tersebut menjadi salah satu alasan mengapa Presiden Trump mendorong renegosiasi NAFTA khususnya dengan Meksiko. Secara komparasi, perbandingan neraca perdagangan antara AS dan Meksiko terlihat dari tabel 1.

Tabel 1. Impor AS dari Meksiko (dalam Miliar US\$) (CRS, 2019).

\begin{tabular}{|l|c|c|c|c|c|c|}
\hline Jenis & 2014 & 2015 & 2016 & 2017 & 2018 & $\begin{array}{l}\% \text { Total } \\
\text { Impor ke } \\
\text { Meksiko }\end{array}$ \\
\hline $\begin{array}{l}\text { Produk minyak } \\
\text { dan batu bara }\end{array}$ & 46.2 & 50.0 & 49.3 & 57.4 & 64.5 & $19 \%$ \\
\hline $\begin{array}{l}\text { Spare part } \\
\text { motor }\end{array}$ & 40.3 & 43.9 & 46.0 & 45.5 & 49.8 & $14 \%$ \\
\hline $\begin{array}{l}\text { Peralatan } \\
\text { komputer }\end{array}$ & 13.8 & 17.1 & 18.2 & 20.2 & 26.6 & $8 \%$ \\
\hline $\begin{array}{l}\text { Semikonduktor } \\
\text { dan komponen } \\
\text { elektronik } \\
\text { lainnya }\end{array}$ & 27.8 & 12.5 & 7.6 & 10.1 & 14.5 & $4 \%$ \\
\hline $\begin{array}{l}\text { Bahan kimia } \\
\text { dasar }\end{array}$ & 10.1 & 10.5 & 10.5 & 11.1 & 11.9 & $3 \%$ \\
\hline Lainnya & 157.5 & 162.4 & 162.3 & 170 & 179.2 & $52 \%$ \\
\hline Total & 295.7 & 296.4 & 293.9 & 314.3 & 346.5 & \\
\hline
\end{tabular}


Tabel 2. Ekspor AS ke Meksiko (dalam Miliar US\$) (CRS, 2019).

\begin{tabular}{|l|c|c|c|c|c|c|}
\hline \multicolumn{1}{|c|}{ Jenis } & 2014 & 2015 & 2016 & 2017 & 2018 & $\begin{array}{l}\% \text { Total } \\
\text { Ekspor ke } \\
\text { Meksiko }\end{array}$ \\
\hline $\begin{array}{l}\text { Produk minyak } \\
\text { dan batu bara }\end{array}$ & 19.6 & 15.4 & 15.9 & 21.6 & 28.8 & $11 \%$ \\
\hline $\begin{array}{l}\text { Spare part } \\
\text { motor }\end{array}$ & 18.4 & 20.8 & 19.8 & 19.8 & 20.2 & $8 \%$ \\
\hline $\begin{array}{l}\text { Peralatan } \\
\text { komputer }\end{array}$ & 15.9 & 16.2 & 16.5 & 15.7 & 17.4 & $7 \%$ \\
\hline $\begin{array}{l}\text { Semikonduktor } \\
\text { dan komponen } \\
\text { elektronik } \\
\text { lainnya }\end{array}$ & 10.9 & 11.4 & 12 & 12.2 & 13.1 & $5 \%$ \\
\hline $\begin{array}{l}\text { Bahan kimia } \\
\text { dasar }\end{array}$ & 10.1 & 8.5 & 8.1 & 9.4 & 10.3 & $4 \%$ \\
\hline Lainnya & 166.1 & 164.2 & 157.8 & 164.6 & 175.2 & $66 \%$ \\
\hline Total & 241.0 & 236.5 & 230.1 & 243.3 & 265 & \\
\hline
\end{tabular}

Mengacu pada tabel 2 perbandingan di atas, pemerintah AS melihat arus perdagangan Meksiko yang lebih besar menjadi ancaman sekaligus masalah terbesar mereka. Meksiko secara garis besar diuntungkan dari perdagangan yang diatur oleh NAFTA tersebut. Sebaliknya, Presiden Trump memberlakukan kebijakan kenaikan tarif pada produk baja Meksiko sebesar 10 persen (Johnson, 2018). Renegosiasi yang dilakukan oleh Presiden Trump ditujukan untuk mencapai kepentingan nasionalnya dalam bidang ekonomi (Cilliza, 2018). Seperti yang dipaparkan oleh Presiden Trump dalam visi misinya yaitu America First, kebijakan renegosiasi NAFTA tidak hanya bertujuan mencapai kepentingan nasional dalam bidang ekonomi, tetapi juga strategi AS untuk dapat memainkan peran sentral di wilayah Amerika Utara (Cilliza, 2018). Dari aspek domestik, kebijakan renegosiasi tersebut diperuntukkan sebagai stimulus dalam membenahi lapangan pekerjaan di AS (Out \& Groch, 2018). Dengan melakukan renegosiasi, setidaknya pemerintah AS berusaha untuk menekan jumlah pekerja asing dari Meksiko dan mengisinya dengan tenaga kerja dari AS sendiri (Out \& Groch, 2018).

Keputusan pemerintah AS untuk melakukan renegosiasi tersebut memang tidak terlepas dari arus perdagangan Meksiko yang secara angka lebih besar daripada AS. Presiden Trump menekankan bahwa kebijakan renegosiasi NAFTA tersebut bertujuan untuk memodernisasi kerja sama perdagangan antara AS dan Kanada serta AS dengan Meksiko pada khususnya (Villareal \& Fergusson, 2019). Hal ini tidak terlepas dari keinginan Presiden Trump yang berusaha untuk mensinergikan arus perdagangan di antara negara-negara yang tergabung dalam rezim NAFTA tersebut (Villareal \& Fergusson, 2019). Dari sisi pemerintah AS, Presiden Trump menginginkan secara kepentingan ekonomi mereka dapat memperoleh keuntungan lebih besar daripada tahun sebelumnya (Polaski et al., 
2019). Pada penelitian yang berjudul Small Gains \& Big Risks: Evaluating the Proposed United States-Mexico-Canada Agreement, pemerintah AS memandang perlu renegosiasi kebijakan tersebut karena beberapa permasalahan seperti pendapatan, standar pekerja dan lingkungan dinilai masih sangat timpang di antara negara yang tergabung dalam NAFTA (Polaski et al., 2019). Dengan adanya kebijakan renegosiasi tersebut, Presiden Trump mengharapkan adanya perlindungan bagi pekerja AS dan masimalisasi pendapatan ekonomi dari perdagangan internasional tersebut (Polaski et al., 2019).

Salah satu faktor yang mempengaruhi kebijakan renegosiasi tersebut pada hakikatnya tidak terlepas dari perumusan kebijakan luar negeri yang melibatkan unsur domestik di dalamnya. Mantan Menlu AS, Henry Kissinger pernah mengatakan bahwa kebijakan luar negeri tidak akan pernah bisa melepaskan keterkaitannya dari peran domestik (Rosenau, 1969). Unsur domestik tersebut dalam studi kebijakan luar negeri sebagai bagian dari internal resources yang dapat mempengaruhi para perumus kebijakan luar negeri di suatu negara (Wittkopf et al., 2008). Melalui keterlibatan unsur domestik, para perumus kebijakan luar negeri akan berusaha untuk memutuskan berbagai macam kebijakan yang sesuai dengan kepentingan nasional mereka (Wittkopf et al., 2008). Terlebih lagi, kebijakan luar negeri merupakan salah satu strategi untuk memenangkan kepentingan nasional di lingkungan eksternalnya (Perwita \& Yani, 2005). Keputusan pemerintah AS yang berusaha untuk mengajukan renegosiasi NAFTA terhadap Meksiko tentunya tidak bisa menafikkan peran domestik di dalamnya. Hal inilah yang akan menjadi rumusan masalah dalam artikel ini. Menurut Eugene Wittkopf, unsur domestik atau internal sources terbagi empat yaitu societal, governmental, role dan individual (Wittkopf et al., 2008). Penulis akan memfokuskan artikel pada konsep governmental terkait peran legislatif dan eksekutif serta kultur politik AS yang berpengaruh terhadap kebijakan renegosiasi NAFTA. Pertanyaan penelitian yang diajukan oleh penulis adalah: "Bagaimana peran governmental sources berpangaruh terhadap kebijakan luar negeri AS terkait renegosiasi NAFTA?".

\section{Tinjauan Pustaka}

Tujuan dari kebijakan luar negeri memiliki tujuan untuk mencapai kepentingan nasional sebuah negara. Hal yang sama berlaku pula bagi pemerintah AS. Bruce Jentleson dalam bukunya yang berjudul American Foreign Policy: The Dynamics of Choice in the 21st Century menjelaskan bahwa ada empat tipe kepentingan nasional yang umumnya hendak dicapai oleh pemerintah AS. Keempat kepentingan nasional tersebut adalah power, principle, prosperity dan peace (Jentleson, 2013). Power merupakan luaran dari kebijakan luar negeri AS yang dicapai melalui mekanisme hard power seperti invasi militer ataupun coercive diplomacy (Jentleson, 2013). Kepentingan nasional ini menurut Jentleson memiliki tujuan untuk melumpuhkan rival pemerintah AS yang dianggap mengancam hegemoni mereka (Jentleson, 2013). Adapun principle merupakan kepentingan nasional AS yang bertujuan untuk menyebarkan values mereka baik secara bilateral maupun multilateral (Jentleson, 2013). Sedangkan prosperity adalah kepentingan nasional AS yang berusaha untuk mencapai keuntungan dan kemakmuran ekonomi 
(Jentleson, 2013). Prosperity pada umumnya dicapai AS dengan memanfaatkan keterlibatan mereka di lembaga keuangan internasional seperti IMF dan Bank Dunia ataupun rezim ekonomi internasional lainnya (Jentleson, 2013). Terakhir, peace adalah wujud dari kepentingan nasional AS yang berusaha untuk terlibat dalam perdamaian dunia seperti keterlibatan negara tersebut di PBB (Jentleson, 2013). Dalam artikel ini, konsep prosperity dijadikan sebagai rujukan mengingat tujuan utama dari renegosiasi NAFTA adalah mempertahankan kepentingan nasional AS dalam bidang ekonomi.

Seperti yang telah dijelaskan pada pembahasan sebelumnya, artikel ini akan memfokuskan kajian pada aspek governmental sources dalam proses kebijakan luar negeri AS. Definisi kebijakan luar negeri seperti yang dipaparkan oleh K.J. Holsti merupakan sebuah strategi yang dilakukan oleh negara-bangsa untuk menghadapi berbagai entitas yang ada di luar batas wilayahnya untuk mencapai kepentingan nasionalnya secara efektif (Holsti, 1992). Eugene Wittkopf dan Charles Kegley menjelaskan bahwa governmental sources merupakan satu dari rangkaian input dalam negeri yang dapat mempengaruhi kebijakan luar negeri AS (Wittkopf et al., 2008). Setidaknya ada empat input internal domestik dalam proses perumusan kebijakan luar negeri AS yaitu societal, governmental, role dan leadership (Wittkopf et al., 2008). Dilihat secara definisi, governmental sources merupakan input domestik dalam kebijakan luar negeri AS berupa sistem pemerintahan negara, rezim yang memerintah di dalam sebuah pemerintahan dan partai politik yang berkuasa di pemerintah AS saat itu (Wittkopf et al., 2008). Menurut Wittkopf dan Kegley, struktur pemerintahan AS dan pola interaksi lembaga intra-pemerintah seperti hubungan politik ekskutif dan legislatif turut mempengaruhi perumusan kebijakan luar negeri AS (Wittkopf et al., 2008). Aspek pemerintahan tersebut pada akhirnya turut berdampak pada perumus kebijakan luar negeri dan proses pembuatan kebijakan tersebut (Wittkopf et al., 2008). Mengutip pendapat John Mearsheimer bahwa ciri khas pemerintah AS yang dikuasai oleh Partai Republik cenderung lebih frontal dan bersifat hard power dalam menjalankan kebijakan luar negerinya (Mearsheimer \& Walt, 2008). Kebijakan Presiden Trump yang menginginkan adanya renegosiasi NAFTA merupakan output yang dipengaruhi oleh governmental sources seperti struktur pemerintahan AS itu sendiri. Inilah yang akan menjadi fokus pembahasan dalam artikel ini. Secara alur, posisi governmental sources dan proses perumusan kebijakan luar negeri sendiri dapat terlihat dari alur funnel of causality yang ditunjukkan pada gambar 1.

Lembaga intra-pemerintah lainnya yang terlibat dalam perumusan kebijakan luar negeri adalah legislatif. Terminologi legislatif di dalam pemerintah AS dikenal dengan nama Kongres (Jentleson, 2013). Adapun Kongres sendiri terbagi menjadi dua kamar karena AS menganut sistem bikameral, yaitu House of Representative dan Senate (Lindsay, 1994). Senat merupakan bagian dari lembaga legislatif AS beranggotakan politisi yang mewakili 50 negara bagian AS (Lindsay, 1994). Senat dalam proses perumusan kebijakan luar negeri memiliki otoritas yang besar karena setiap proposal kebijakan luar negeri yang diajukan oleh Presiden harus mendapatkan persetujuan minimal $2 / 3$ suara dari mayoritas anggota Senat (US Senate, 2019). Dalam proses perumusan kebijakan luar negeri yang melibatkan 
aspek perdagangan internasional, Senat memiliki sub-komite seperti Committee of Foreign Relations dan Sub-committee on Fiscal Responsibility and Economic Growth yang memiliki kewenangan untuk ikut mengusulkan kepentingan nasional dalam draft kebijakan luar negeri yang diajukan oleh Presiden (US Senate, 2019). Di satu sisi, HoR memiliki dua tugas utama dalam proses perumusan kebijakan luar negeri AS seperti substantive legislation menjelaskan kebijakan apa saja yang boleh dan tidak boleh dilakukan oleh pemerintah AS (Jentleson, 2013). Adapun tugas kedua adalah procedural legislation seperti meminta keterangan Presiden bagaimana kebijakan tersebut dibuat (Jentleson, 2013). Tidak hanya itu HoR memiliki wewenang untuk memutuskan anggaran yang akan digunakan oleh Presiden untuk menjalankan kebijakan tersebut (Jentleson, 2013). Selain itu, presiden harus dapat meyakinkan HoR dalam proses hearing (dengar pendapat) agar usulan kebijakan luar negeri tersebut mendapatkan persetujuan 2/3 anggota HoR (Jentleson, 2013).

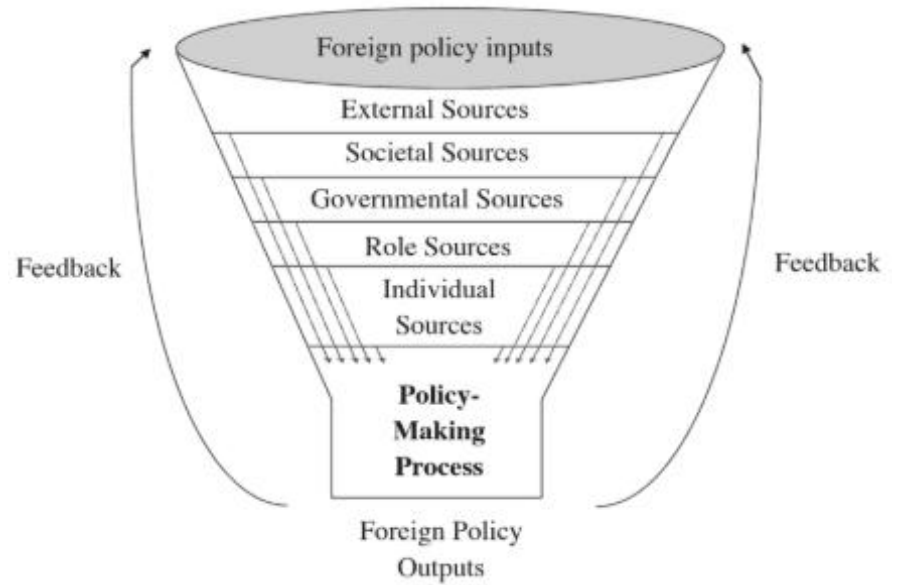

Gambar 1. Alur funnel of causality (Wittkopf et al., 2008).

\section{METODE}

Metode penulisan artikel ilmiah dalam jurnal ini menggunakan metode kualitatif. John Creswell menyatakan bahwa penelitian kualitatif merupakan bentuk penelitian yang menggunakan teks dan bahasa sebagai alat analisis dalam mengkaji sebuah fenomena (Creswell, 2014). Penggunaan metode kualitatif dalam artikel ini berbeda dengan kuantitatif karena metode tersebut pada umumnya menggunakan teknik observasi, wawancara, studi pustaka dalam bentuk dokumen maupun audio visual (Creswell, 2014). Selain itu, Creswell tidak menafikkan bahwa dalam metode kualitatif terdapat unsur reflektivis yang berarti bahwa sudut pandang penulis atau peneliti sangat menentukan dalam membentuk narasi argumen yang tertuang dalam bab analisis (Creswell, 2014). Metode kualitatif relevan dengan topik dalam artikel ini karena penelitian kualitatif digunakan apabila peneliti ingin membahas sebuah fenomena sosial seperti kebijakan, program maupun kejadian-kejadian tertentu (Creswell, 2014). Adapun pendekatan penulisan dalam artikel ini menggunakan studi kasus. Case study research menurut Laura Roselle dan Sharon Spray berarti 
sebuah fenomena, kasus atau isu dalam studi hubungan internasional yang hendak dikaji menggunakan kerangka teoritis maupun konseptual (Roselle \& Spray, 2012). Kasus dalam artikel adalah aspek governmental sources dalam kebijakan renegosiasi AS di rezim NAFTA. Terkait dengan pengumpulan data untuk menunjang argumen dalam bab analisis, penulis menggunakan teknik studi pustaka yang diambil dari jurnal, data pemerintah maupun dokumen audio visual yang kredibel (Creswell, 2007).

\section{HASIL DAN PEMBAHASAN}

Pembahasan tentang renegosiasi NAFTA oleh pemerintah AS seperti yang telah ditekankan pada pembahasan sebelumnya berkaitan erat dengan unsur governmental sources dalam proses perumusan kebijakan luar negeri negara tersebut. Eugene Wittkopf telah menegaskan bahwa governmental sources adalah input internal yang melibatkan proses politik lembaga intra pemerintah seperti relasi eksekutif dan legislatif serta kultur politik yang didominasi partai yang berkuasa di AS saat itu (Wittkopf et al., 2008). Relasi eksekutif dan legislatif tersebut tertuang dalam uraian Bruce W. Jentleson bahwa di antara Presiden dan Kongres perlu ada mekanisme check and balance agar tidak penyalahgunaan wewenang (Jentleson, 2013). Posisi eksekutif dan cabang departemennya dalam perumusan kebijakan luar negeri AS memang memiliki posisi penting. Akan tetapi, pada setiap proses perumusan kebijakan luar negeri khususnya dalam renegosiasi NAFTA, keberadaan Senat tidak kalah penting seperti halnya Presiden. Sesuai yang tertuang dalam Article I Section 8 Constitution of United States, Senat memiliki wewenang untuk mengkaji undang-undang yang diajukan oleh House of Representative (HoR), menolak dan menyetujui perjanjian internasional, menyetujui dan menolak undangundang yang disusun oleh HoR dan bahkan terlibat bersama Presiden dalam pembuatan kebijakan luar negeri (Jentleson, 2013). Terkait dengan kasus renegosiasi NAFTA sendiri, keputusan pemerintah AS yang berusaha untuk mengubah aturan dalam rezim internasional tersebut tidak terlepas dari keterikatan unsur intra pemerintah di dalamnya seperti Presiden dan Kongres.

Hal lainnya yang menarik untuk menjadi pembahasan adalah komposisi dari jumlah Partai Republik yang menduduki jabatan di Senat AS. Total politisi Partai Republik yang menduduki jabatan di Senat AS berjumlah 51 orang dari 100 anggota Senat (Cilliza, 2018). Dengan komposisi Senat yang dikuasai oleh Partai Republik, eksekutif AS hanya perlu mendapatkan dukungan 1/3 suara di Senat AS untuk dapat meloloskan kebijakan renegosiasi NAFTA. Di sisi lain, program renegosiasi NAFTA dapat berjalan sesuai dengan rencana apabila eksekutif khususnya Presiden dapat meyakinkan anggota HoR yang dikuasai oleh Partai Demokrat. Data terakhir yang dirilis oleh Congressional Research Service (CRS) memaparkan bahwa komposisi Partai Demokrat di lembaga HoR berjumlah 236 orang dan Partai Republik sendiri diwakili elit politiknya sebanyak 198 orang (CRS, 2020). Proses perumusan kebijakan luar negeri ini tidak dapat muncul dengan sendirinya. Artinya adalah Presiden dalam mengajukan proses renegosiasi NAFTA tidak dapat secara otoriter menjalankan kebijakan tersebut tanpa ada proses check and balance dari legislatif. Senator dari Partai Republik yang bernama Gordon Smith pernah 
mengatakan bahwa kebijakan luar negeri yang disusun oleh pemerintah AS harus bersifat bipartisan dan sinergi antara legislatif dan eksekutif (Siegel, 2000). Oleh karenanya, kebijakan renegosiasi NAFTA ini dianggap bersinergi apabila telah melalui proses politik baik di tingkat eksekutif maupun di legislatif.

Proses renegosiasi NAFTA ini bermula dari keinginan Presiden Trump untuk meninjau kembali beberapa aturan yang diyakini sangat memberatkan perekonomian AS. Pada tahun 2017, Presiden Trump mengajukan dua opsi terkait renegosiasi NAFTA yaitu pemerintah AS keluar dari keanggotaan NAFTA atau meninjau kembali syarat-syarat perdagangan yang berusaha untuk dimodernisasi (Bedard \& Nelson, 2017). Pemerintah AS meminta kepada dua anggota rezim NAFTA lainnya yaitu Meksiko dan Kanada untuk melakukan renegosiasi beberapa standar seperti upah buruh, bea cukai, dan strategi setiap negara anggota untuk melakukan ekspansi pasar (Bedard \& Nelson, 2017). Selain itu, Presiden Trump pun mendorong adanya aturan yang membahas tentang perdagangan digital, standar aturan pekerja, hak kekayaan intelektual dan standar layanan di dalam proses renegosiasi tersebut (USTR, 2017). Keinginan Presiden Trump tersebut tidak bisa dimungkiri bahwa AS berusaha untuk mengejar kembali perekonomiannya yang tertinggal khusunya defisit perdagangan dari Meksiko. Pada data yang telah dipaparkan pada pembahasan sebelumnya, pemerintah AS memiliki defisit perdagangan yang cukup jauh dari Meksiko sebesar 30 miliar dollar AS (CRS, 2019). Presiden Trump pada dasarnya merupakan seorang pengusaha dan hal tersebut mendorong dirinya untuk meningkatkan perekonomian AS lebih maju ketimbang Meksiko. Peningkatan perekonomian sebagai ouput dalam kebijakan luar negeri merupakan bagian dari unsur proseperity yaitu pertumbuhan dan neraca perdagangan AS harus lebih menguntungkan (Jentleson, 2013).

Proses pertama renegosiasi NAFTA adalah perancangan proposal yang dilakukan oleh eksekutif dan departemen yang berada di bawah naungannya. Presiden merumuskan kebijakan renegosiasi bersama dengan National Economic Council (NEC), Department of State (DoS), Department of Commerce (DoC), Department of Treasury (DoT), US Trade Representative (USTR) dan International Trade Commision atau ITC (Villareal \& Fergusson, 2019). Dalam proses perumusan kebijakan renegosiasi NAFTA ini, NEC memiliki kewenangan sebagai penasihat utama Presiden dalam bidang ekonomi terkait dengan imbas dari masifnya impor Meksiko di AS sehingga mengakibatkan neraca perdagangan AS defisit (Villareal \& Fergusson, 2019). Tidak hanya itu, NEC berusaha untuk memastikan bahwa kebijakan renegosiasi NAFTA sesuai dengan program ekonomi utama AS dan tercapainya kepentingan nasional dalam bidang ekonomi (Villareal \& Fergusson, 2019). Sedangkan DoC memberikan analisis dan masukkan kepada Presiden Trump untuk mengkaji prospek bisnis apa saja yang dapat dikembangkan dari renegosiasi NAFTA tersebut seperti peningkatan komoditas agrikultur ataupun produk energi dan industri (Villareal \& Fergusson, 2019). Di sisi lain, ITC yang berdiri sebagai badan independen dalam eksekutif AS berusaha untuk memetakan dan menganalisis dampak apa saja yang terjadi dari defisit perdagangan di NAFTA dengan Meksiko ini di seluruh negara bagian yang ada di AS (Villareal \& Fergusson, 2019). Seluruh rekomendasi tersebut ditelaah oleh DoT untuk selanjut dikaji apakah kebijakan 
Presiden Trump untuk melakukan renegosiasi tersebut tidak memiliki dampak terhadap stabilitas keuangan dan ekonomi AS (Villareal \& Fergusson, 2019). Terakhir, DoS atau kemenlu AS memberikan masukan terkait situasi terkini dalam perekonomian internasional dan respon pemerintah Meksiko dari proposal AS untuk melakukan renegosiasi (Villareal \& Fergusson, 2019). Tidak hanya itu DoS pun menjadi garda terdepan diplomasi AS dalam renegosiasi NAFTA dengan pemerintah Meksiko (Villareal \& Fergusson, 2019).

Proses selanjutnya dalam perumusan renegosiasi NAFTA adalah presiden mengajukan proses negosiasi kebijakan tersebut kepada Senat. Dalam aspek governmental sources khususnya peran Senat dalam perumusan kebijakan luar adalah lembaga legislatif tersebut memiliki wewenang untuk memberikan masukan sekaligus menjadi wadah konsultasi dalam menentukan arah kebijakan luar negeri AS (Jentleson, 2013). Secara analisis kebijakan luar negeri, Senat mengirimkan komite di bawahnya seperti Council on Foreign Relations dan Subcommittee on Fiscal Responsibility and Economic Growth (Villareal \& Fergusson, 2019). Peneliti menganalisis bahwa keterlibatan dua komite Senat AS tersebut bertujuan untuk memberikan feedback terkait isu renegosiasi yang berdampak pada negara bagian (Villareal \& Fergusson, 2019). Senat pada dasarnya terpilih dari perwakilan 50 negara bagian AS dan memiliki tugas memberikan konsultasi terkait dampak kebijakan luar negeri AS terhadap konstituennya di negara bagian (Jentleson, 2013). Oleh karenanya, Senat perlu mempertimbangkan dan memberikan konsultasi kepada Presiden terkait dampak kebijakan renegosiasi NAFTA tersebut. Council on Foreign Relations memberikan konsultasi strategi seperti apa saja yang harus dilakukan oleh Presiden untuk melakukan renegosiasi dengan membawa aspirasi dari setiap negara bagian. Sama halnya seperti Council on Foreign Relations, keberadaan Subcommittee on Fiscal Responsibility and Economic Growth bertujuan untuk memberikan masukan kepada Presiden terkait bagaimana renegosiasi NAFTA dapat meningkatkan pertumbuhan perekonomian AS. Kebijakan renegosiasi tersebut diharapkan dapat menstimulus peningkatan perekonomian di setiap negara bagian yang ada di AS. Hasil dari konsolidasi dan konsultasi politik yang dilakukan oleh Presiden Trump adalah keputusan Senat untuk menyetujui proposal eksekutif dengan perbandingan 89 setuju renegosiasi dan 10 menolak usulan Presiden tersebut (Kirby, 2020a). Setelah persetujuan tersebut, Presiden dan jajaran departemennya perlu meyakinkan House of Representative untuk mewujudkan kebijakan renegosiasi NAFTA.

Proses selanjutnya dalam penentuan arah kebijakan renegosiasi NAFTA adalah dengar pendapat dan voting yang dilakukan di ranah House of Representative (HoR). Fungsi utama HoR dalam perumusan kebijakan luar negeri AS bertindak sebagai substantive dan procedural legislation (Jentleson, 2013). Secara kelembagaan, HoR akan mempertanyakan substansi dari kebijakan renegosiasi tersebut sedangkan pada aspek prosedural mereka akan menelisik apakah draft kebijakan renegosiasi telah melalui tahapan dengar pendapat di Senat. Pada tahapan dengar pendapat dengan HoR, Presiden dan United States Trade Representative (USTR) melakukan lobi politik agar kebijakan renegosiasi tersebut dapat terwujud (Kirby, 2020b). Proses lobi diperlukan agar eksekutif mendapatkan dukungan 
minimal 2/3 suara dari HoR. Kendala yang dihadapi oleh eksekutif adalah mayoritas partai yang menguasai HoR merupakan oposisi dari Partai Repulik yaitu Partai Demokrat (CRS, 2020). Seperti yang diutarakan oleh Senator Gordon Smith bahwa proses perumusan kebijakan luar negeri yang baik adalah bipartisan dan sinergi intra-pemerintah (Siegel, 2000). Hal ini tidak terlepas dari pentingnya persetujuan HoR agar kebijakan renegosiasi NAFTA tersebut telah melalui proses politik di tingkat eksekutif, Senat dan HoR. Tanpa adanya dukungan dari HoR, maka kebijakan renegosiasi NAFTA sulit untuk diwujudkan. Pada praktiknya, HoR yang dikuasai oleh Partai Demokrat menyetujui rancangan kebijakan renegosiasi NAFTA dengan jumlah voting 385 berbanding 41 (Kirby, 2020a). Partai Demokrat menyetujui draft kebijakan renegosiasi NAFTA dengan catatan, Presiden Trump harus melindungi hak-hak pegawai, lingkungan, pembukaan pangsa pasar bagi agrikultur AS khususnya produk olahan susu, perlindungan kekayaan hak intelektual dan nol tarif bagi ekspor-impor produk suku cadang otomatif (Kirby, 2020a). Dengan disetujuinya kebijakan renegosiasi tersebut, maka Presiden Trump dapat menjalankan kebijakannya setelah melalui proses check and balance. Proses perumusan kebijakan renegosiasi itu dapat diturunkan dari bagan di bawah ini sesuai dengan alur Funnel of Causality seperti pada gambar 2.

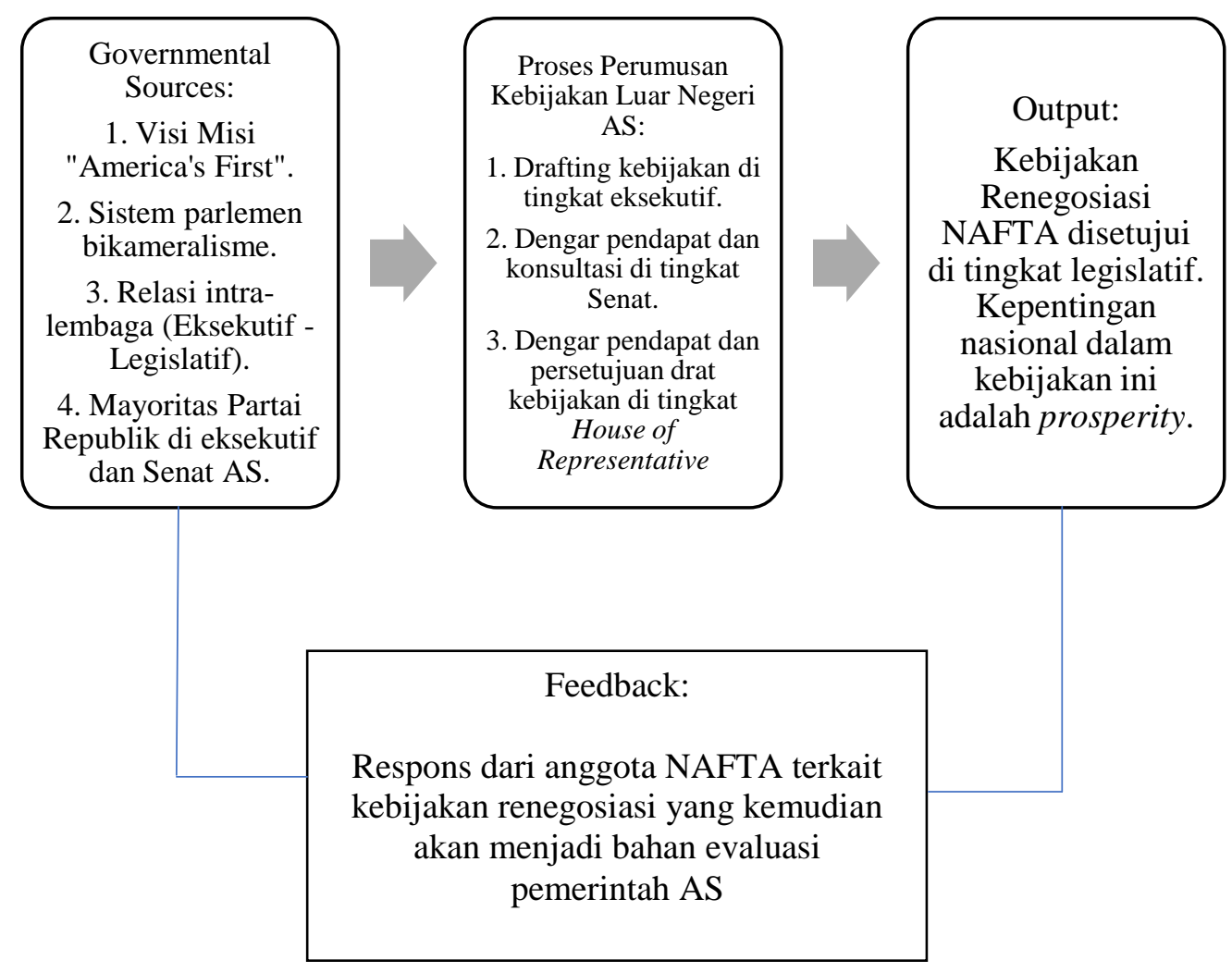

Gambar 2. Proses Perumusan Kebijakan AS Terkait Renegosiasi NAFTA 
Proses perumusan kebijakan renegosiasi NAFTA tersebut tidak bisa terlepas dari visi misi Presiden Trump yang sangat bersifat inward looking dan memprioritaskan kepentingan nasional AS di atas segalanya. Jalannya perumusan kebijakan renegosiasi tersebut memiliki korelasi dengan unsur governmental sources lainnya seperti sistem parlemen AS yang bersifat bikameral atau dua sistem. Hal ini tentunya berpengaruh pada proses perumusan kebijakan renegosiasi NAFTA yaitu draft usulan Presiden harus mendapatkan persetujuan di Senat dan HoR. Persetujuan parlemen AS (Senat dan HoR) sangat krusial untuk mewujudkan kebijakan renegosiasi tersebut. Sehingga relasi politik intra lembaga antara eksekutif dan legislatif menjadi penting. Terlepas dari komposisi mayoritas eksekutif dan Senat yang dikuasi oleh Partai Republik, HoR tetap dikuasi oleh Partai Demokrat. Proses lobi politik memainkan peranan penting terkait bagaimana draft yang sudah disetujui oleh Senat mendapatkan persetujuan dari HoR. Proses lobi politik yang dilakukan oleh perwakilan eksekutif AS dan USTR cukup berhasil untuk meyakinkan Partai Demokrat untuk meloloskan draft kebijakan renegosiasi NAFTA (Kirby, 2020a). Juru bicara HoR yaitu Nancy Pelosi mengatakan bahwa perbedaan politik antara HoR dan Presiden Trump serta isu pemakzulan tidak menghalangi lembaganya untuk mencapai kepentingan nasional AS dalam bidang ekonomi (Kirby, 2020a).

\section{SIMPULAN}

Keinginan Presiden Trump untuk mewujudkan kebijakan renegosiasi NAFTA melalui jalan yang panjang dan berliku. Hal ini tidak terlepas dari unsur governmental sources sendiri seperti sistem parlemen AS yang bersifat bikameral dan juga sistem negaranya yang berasaskan demokrasi. Oleh karenanya, proses kebijakan renegosiasi yang diajukan oleh Presiden Trump harus mendapatkan persetujuan dari Senat dan HoR. Posisi Senat sebagai perwakilan negara bagian AS menjadi media konsultasi Presiden sekaligus memberikan masukan seperti apa saja kebijakan renegosiasi tersebut yang dapat bermanfaat bagi rakyat AS yang berada di 50 negara bagian. Sedangkan HoR akan menitikberatkan pada aspek substantif dan prosedural sekaligus memastikan bahwa kebijakan renegosiasi NAFTA tersebut memang bermanfaat bagi kepentingan nasional AS di bidang ekonomi. Keberadaan HoR sama pentingnya seperti Senat karena lembaga tersebut adalah pintu terakhir dari terwujudnya kebijakan renegosiasi NAFTA. Pada akhirnya, draft kebijakan renegosiasi NAFTA berhasil mendapatkan persetujuan baik dari Senat dan HoR sehingga secara bipartisan kebijakan tersebut sudah sesuai dengan proses check and balance.

\section{DAFTAR PUSTAKA}

Anjani, A. (2018). Kepentingan Amerika Serikat Keluar dari Trans Pasific Partnership Di Masa Pemerintahan Donald Trump.

Arce, J. (2019). Trump's Anti-Immigrant Rhetoric Was Never About Legality - It Was About Our Brown Skin. https://time.com/5645501/trump-antiimmigration-rhetoric-racism/. 
Bedard, J., \& Nelson, T. G. (2017). What to Expect From NAFTA Renegotiations. https://www.skadden.com/insights/publications/2017/07/what-to-expectfrom-nafta-renegotiations.

Cilliza, C. (2018). Donald Trump Used A Word 'He's 'Not Supposed To'. Here's Why. https://edition.cnn.com/2018/10/23/politics/donald-trumpnationalism/index.html.

Creswell, J. (2007). Qualitative Inquiry and \& Research Design: Choosing Among Five Approaches. London: SAGE.

Creswell, J. (2014). Research Design: Qualitative, Quantitative and Mixed Methods Approaches (4th Eds). London: SAGE.

CRS. (2019). U.S.-Mexico Economic Relations: Trends, Issues, and Implications. https://fas.org/sgp/crs/row/RL32934.pdf.

CRS. (2020). Membership of the 116th Congress: A Profile. https://fas.org/sgp/crs/misc/R45583.pdf

Goodwin, D., \& Johnson, L. (1976). The American Dream. New York: Harper and Row.

Holsti, K. (1992). International Politics A Framework for Analysis (6th eds). New Jersey: A Simon \& Schuster Company.

Jentleson, B. W. (2013). American Foreign Policy: The Dynamics of Choice in the 21st Century (Fifth Edition). Duke University: W.W Norton \& Company.

Johnson, K. (2018). Here Comes Trump's Trade War. https://foreignpolicy.com/2018/03/01/here-comestrumpstrade-war- $\quad$ steelaluminum-tariffs-232/.

Kirby, J. (2020a). The Senate Has Approved the USMCA, Bringing Trump's Trade Deal One Step Closer to Reality. https://www.vox.com/2020/1/16/21067782/usmca-senate-vote-trump-nafta2-0-canada-mexico.

Kirby, J. (2020b). The USMCA Trade Deal Passes the House in a Rare Bipartisan Vote. https://www.vox.com/policy-andpolitics/2019/12/19/21013178/usmca-trade-deal-passes-house-vote-approvebipartisan-nafta-trump.

Lindsay, J. (1994). Congress and the Politics of U.S. Foreign Policy. USA: Foreign Affairs. 
Mearsheimer, J., \& Walt, S. M. (2008). The Israel Lobby and U.S Foreign Policy. New York: Farrar, Starus \& Giroux.

Moran, R. T., \& Abbot, J. (1994). NAFTA: Managing the Cultural Differences. Houston: Gulf Publishing Company.

NY Times. (2017). Presidential Election Results: Donald J. Trump Wins. https://www.nytimes.com/elections/2016/results/president.

Out, U., \& Groch, M. (2018). Renegotiated NAFTA Deal: Improvements on Some Key Demands and More Work Needed.

Perwita, A. A., \& Yani, Y. (2005). Pengantar Ilmu Hubungan Internasional. Bandung: Rosdakarya.

Polaski, S., Gallagher, K., \& Capaldo, J. (2019). Small Gains \& Big Risks: Evaluating the Proposed United States - Mexico - Canada Agreement.

Pompeo, M. (2019). On the U.S. Withdrawal from the Paris Agreement.

Roselle, L., \& Spray, S. (2012). Research and Writing in International Relations. Boston: Pearson Longman.

Rosenau, J. (1969). International Politics and Foreign Policy (eds). New York: The Free Press.

Siegel, J. (2000). U.S Foreign Policy Agenda. https://www.loc.gov/item/2002230618/.

Trubowitz, P. (2011). Politics and Strategy: Partism Ambition and American Statecraft. New Jersey: Princeton University Press.

Trump, D. J. (2016). Trump Foreign Policy Speech. https://www.donaldjtrump.com/press-releases/donald-j-trump-foreignpolicy-speech.

US Senate. (2019). International Relations. https://www.senate.gov/reference/reference_index_subjects/International_R elations_vrd.htm.

USTR. (2017). USTR Releases NAFTA Negotiating Objectives. https://ustr.gov/about-us/policy-offices/press-office/pressreleases/2017/july/ustr-releases-nafta-negotiating.

Villareal, M., \& Fergusson, I. (2019). NAFTA Renegotiation and the Proposed 
United States- Mexico - Canada Agreement (USMCA).

Wittkopf, E., Jones, C., \& Kegley, C. W. (2008). American Foreign Policy: Pattern and Process. Thompson Higher Education.

Yuliantoro, N. R., Prabandari, A., \& Agussalim, D. (2017). Pemilihan Presiden Tahun 2016 dan Politik Luar Negeri Amerika Serikat. Jurnal Hubungan Internasional, $5(2)$, 193-209. https://doi.org/https://doi.org/10.18196/hi.5297. 